\title{
Corrigendum: Dynamics of Mechanisms with Cams Illustrated in the Classical Distribution
} ${ }^{1}$ Relly Victoria Virgil Petrescu, ${ }^{2}$ Raffaella Aversa, ${ }^{3}$ Bilal Akash, ${ }^{4}$ Ronald Bucinell, ${ }^{5}$ Juan Corchado, ${ }^{6}$ Samuel P.
Kozaitis, ${ }^{7}$ Taher M. Abu-Lebdeh, ${ }^{2}$ Antonio Apicella and ${ }^{1}$ Florian Ion Tiberiu Petrescu

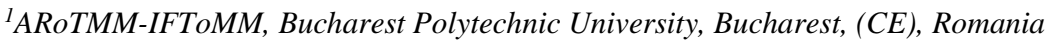

${ }^{2}$ Advanced Material Lab, Department of Architecture and Industrial Design,

Second University of Naples, 81031 Aversa (CE), Italy

${ }^{3}$ Dean of School of Graduate Studies and Research, American University of Ras Al Khaimah, UAE

${ }^{4}$ Union College, USA

${ }^{5}$ University of Salamanca, Spain

${ }^{6}$ Florida Institute of Technology, USA

${ }^{7}$ North Carolina A and T State University, USA

Correction to: American Journal of Engineering and Applied Sciences

http://doi.org/10.3844/ajeassp.2017.551.567, published online 05 June 2017; updated

29 August 2019

The original version of this Article contained Mr. MirMilad Mirsayar as a Co-

Author. Mr. Mirsayar has not contributed to the preparation and publication of this manuscript.

These errors have now been corrected in the HTML and PDF versions of the Article. http://doi.org/10.3844/ajeassp.2017.551.567. 